\title{
Establishment of performance-based seismic design factors for precast concrete floor diaphragms
}

\author{
Dichuan Zhang, Robert B. Fleischman
}

- School of Engineering

\begin{abstract}
This paper presents an analytical study used to establish design factors for a new seismic design methodology for precast concrete floor diaphragms. The design factors include diaphragm force amplification factors $\Psi$ and diaphragm shear overstrength factors $\Omega_{\mathrm{v}}$. The $\Psi$ factors are applied to the ASCE7-05 diaphragm design forces to produce diaphragm design strengths aligned to different performance targets. These performance targets are based on diaphragm detailing choices, and include: (i) elastic diaphragm behavior or (ii) limiting inelastic deformation demand on the diaphragm reinforcement (connectors between precast units or reinforcing bars in a topping slab) to within their reliable deformation capacities. The $\Omega_{\mathrm{v}}$ factors provide overstrength relative to the diaphragm bending strength for capacity protection against shear failure. The analytical study was performed by conducting nonlinear time history analyses of a simple evaluation structure, of which the dimensions and structural properties were varied. The analytical model used in the study is constructed and calibrated on the basis of extensive physical testing. The analytically obtained values of the diaphragm design factors are presented as functions of the geometric and structural properties of the building. The design factors presented here have been verified through evaluation of a set of realistic precast prototype structures. The diaphragm design methodology is currently in the codification process.
\end{abstract}
Original language
English
Pages (from-to)
$675-698$

Number of pages

24

Journal

$\underline{\text { Earthquake Engineering and Structural Dynamics }}$

Volume

45

Issue number

5

State

Published - Apr 252016

Zhang, D., \& Fleischman, R. B. (2016). Establishment of performance-based seismic design factors for precast concrete floor diaphragms. Earthquake Engineering and Structural Dynamics, 45(5), 675-698. DOI: 10.1002/eqe.2679 